\title{
Thermal Inactivation of Newcastle Disease Virus
}

\section{Coupled Inactivation Rates of Hemagglutinating and Neuraminidase Activities}

\author{
JOHN S. PIERCE ${ }^{1}$ AND A. M. HAYWOOD ${ }^{2}$ \\ Department of Microbiology, Yale University School of Medicine, New Haven, Connecticut 06510
}

Received for publication 7 July 1972

\begin{abstract}
The thermal stability of Newcastle disease virus has been characterized in terms of the rate constants for inactivation of hemagglutinating activity (HA), neuraminidase activity (NA), and infectivity. Inactivation of HA results in the concomitant loss of NA. Infectivity, however, is much more thermolabile. Disintegration of the virus particle is not responsible for the identical rate constants for inactivation of HA and NA, nor is their parallel inactivation uncoupled in envelope fragments produced by pretreating the virus with phospholipase-C. The data indicate that a common envelope factor(s) can influence the thermal stability of both activities.
\end{abstract}

Myxoviruses have been frequently characterized with regard to the thermal stability of their hemagglutinating activity (HA), neuraminidase activity (NA), and infectivity. Yet, little is known about the nature of the factors responsible for a given thermal stability. Comparative studies have shown that, under the stress of heat, infectivity is usually destroyed first, followed by the loss of $\mathrm{HA}$, and finally NA $(5,13,26)$. This order of increasing stabilities might reflect the degree of structural integrity required of the entity possessing the activity. That is, infectivity is characteristic of an intact virion; whereas, a polyvalent subvirion hemadsorbing unit can still elicit hemagglutination, and NA is demonstrable in an even less organized structure $(5,8,9,12,17,19,21$, $34)$. However, there are notable exceptions. One report shows that Newcastle disease virus infectivity and HA are inactivated at the same rate (11). Among the A2 (Asian) strains of influenza virus (15) and in the CA type-2 parainfluenza virus (5), HA is more thermolabile than infectivity; however, NA persists after infectivity is completely destroyed. Furthermore, there are other examples, where NA is apparently more thermolabile than HA (13).

${ }^{1}$ Present address: Biology Division, California Institute of Technology, Pasadena, Calif. 91109.

${ }^{2}$ Present address: Institute of Animal Physiology, Babraham, Cambridge, England.
The rate of thermal inactivation of the soluble forms of HA and NA may be different from that characteristic of the envelope-integrated forms of these activities. For example, lowmolecular-weight hemagglutinin can be more thermolabile than the capacity of the intact virus to hemagglutinate (12). In addition, the thermal stability of NA is often markedly reduced when the activity is separated from the virion surface in the form of a 9 to $10 \mathrm{~s}$ particle (9).

Thus, it seems clear that the thermal stability of myxoviral HA, NA, and infectivity may be influenced by factors at more than one level of organization. In this communication we describe the isolation of virus clones whose HA and NA are either both thermostable or both thermolabile. The identical kinetics with which both activities of a given isolate inactivate suggests that a common factor(s) influences their stability as they exist in the envelope-integrated state. (The results presented here are part of a thesis by John S. Pierce submitted to Yale University in partial fulfillment of the requirements for the Ph.D. degree.)

\section{MATERIALS AND METHODS}

Virus strains. The following strains of Newcastle disease virus (NDV) were obtained in the form of lyophilized infectious allantoic fluid from the NDV 
repository at the University of Wisconsin, Madison: (I) Texas-GB-1848, (II) California-11914-1944 (NAP), (III) California-11914-1944 (FD), (IV) California1944 (RO), (V) New Jersey-Roakin-1946 (FRB), (VI) New Jersey-Roakin-1946 (Daubrey), (VII) New Jersey-LaSota-1946, (VIII) Massachusetts-MK 107 (L)-1945, and (IX) Connecticut-Luginbuhl-1955. Each strain was repassaged in eggs, and the resulting infectious allantoic fluids (IAFs) were stored in small volumes at $-70 \mathrm{C}$.

Cell culture. Primary chicken embryo fibroblasts were prepared by the method of Hsuing (16). Monolayers were grown out at $37 \mathrm{C}$ in minimum essential medium (Eagle [MEM] buffered with Hanks salts (GIBCO, Inc.) and contained 5\% fetal bovine serum (Microbiological Associates, Inc.), and $0.01 \%$ lactalbumin hydrolysate (GIBCO, Inc.). Confluent monolayers were maintained at the same temperature in MEM buffered with Earle salts and contained $2 \%$ fetal bovine serum (maintenance medium).

Virus growth. In eggs: NDV stocks were diluted in cold phosphate- $\mathrm{NaCl}$ buffer $(0.02 \mathrm{M}$ sodium phosphate, $0.15 \mathrm{M} \mathrm{NaCl}$ ), $p \mathrm{H}$ 7.0. Fifty-microliter amounts were inoculated by the allantoic route into 11-day-old embryonated eggs. Following $48 \mathrm{hr}$ of incubation in a moist atmosphere at $36 \mathrm{C}$, the eggs were chilled to $4 \mathrm{C}$. IAF was harvested, clarified by low-speed centrifugation, and stored at $-70 \mathrm{C}$.

In cell culture: before being infected, monolayers were washed with Hanks balanced salts solution (GIBCO, Inc.) that had been prewarmed to room temperature. Virus was allowed to adsorb to the cells for $1 \mathrm{hr}$ at room temperature. After the inoculum was removed, fresh maintenance medium was added and the cultures were returned to $37 \mathrm{C}$. When cytolysis was pronounced, but not maximal, the infectious cell culture fluid bathing the cells was harvested, clarified, and stored as described above.

Infectivity titrations. Infectivity was determined by standard plaque assay procedures (16). Material to be tested was diluted in cold phosphate- $\mathrm{NaCl}$ buffer, $p H$ 7.0, and 0.1-ml volumes of the appropriate dilutions were inoculated onto duplicate confluent 25- $\mathrm{cm}^{2}$ monolayers in Falcon T-flasks. After adsorption, the cells were overlayered with $5 \mathrm{ml}$ of molten maintenance medium containing $0.0033 \%$ neutral red and $0.9 \%$ Special Noble agar (Difco). When the medium solidified, the flasks were inverted and incubated at $37 \mathrm{C}$ in the dark. Final plaque counts were made on the fourth day.

Cloning. Isolates were cloned from stock virus populations by plaque purification and were subsequently passaged in chick cells or eggs, or both. The resulting infectious fluids were stored in small volumes at $-70 \mathrm{C}$.

Virus purification. Virus was purified by a modification of the methods of Duesberg (10) and Pons (27). All steps were carried out at 0 to 4 C. A $20-\mathrm{ml}$ amount of clarified infectious material, in a $28-\mathrm{ml}$ cellulose nitrate centrifuge tube, was underlayered with $4 \mathrm{ml}$ of Tris-EDTA-NaCl buffer [0.01 M tris(hydroxymethyl)aminomethane-hydrochloride, 0.001 $\mathrm{M}$ ethylenediaminetetraacetic acid, $0.05 \mathrm{M} \mathrm{NaCl}, p \mathrm{H}$
7.0] containing $60 \%(\mathrm{w} / \mathrm{v})$ sucrose and $17.5 \%(\mathrm{w} / \mathrm{v})$ potassium tartrate (density $=1.30 \mathrm{~g} / \mathrm{ml}$ ). After $1.5 \mathrm{hr}$ of centrifugation at $25,000 \mathrm{rpm}$ in an SW25.1 rotor of a Spinco model $L$ ultracentrifuge, the bottom of the tube was pierced, and small fractions were collected across the steep density gradient created in the region of the interphase. Peak virus fractions (monitored as HA) were pooled and either dialyzed against an appropriate buffer and stored at $-70 \mathrm{C}$, or purified further by first diluting the sample to reduce the density to $1.07 \mathrm{~g} / \mathrm{ml}$ and then layering it onto a 24-ml linear potassium tartrate gradient (10 to $40 \%[\mathrm{w} / \mathrm{v}$ ] in Tris-EDTA-NaCl buffer). Virus was brought to its isopycnic density $(1.19 \mathrm{~g} / \mathrm{ml})$ by centrifugation at $24,000 \mathrm{rpm}$ for $4.5 \mathrm{hr}$. Gradients were fractionated, and the peak virus fractions were pooled, dialyzed, and stored at $-70 \mathrm{C}$. Sometimes the densities of selected fractions were determined from refractive indices read in a Zeiss refractometer at $25 \mathrm{C}$.

Thermal inactivations. Samples to be inactivated were delivered into soft glass tubes that measured 75 by $12 \mathrm{~mm}$ with an inner diameter of $10 \mathrm{~mm}$. After equilibration in an ice-water bath, the tubes (with the exception of zero-time controls) were transferred in series to a swirling water bath set at $56 \pm 0.5 \mathrm{C}$. At appropriate times thereafter, they were returned to the ice-water bath. Samples were then assayed for surviving biological activity.

When appropriate, the data during periods of exponential decline in activity are presented in terms of the rate constant ( $k$, expressed as minutes ${ }^{-1}$ ), defined in the following equation for a first-order inactivation: $2.3 \log _{10}\left(\mathrm{~N} / \mathrm{N}_{\mathrm{o}}\right)=-k \mathrm{t}$, where $\mathrm{N}_{\mathrm{o}}$ represents the original activity and $\mathrm{N}$, the activity at some time, $t$, after heating. Unless otherwise stated, $k$ was calculated from the slope of the line drawn by the method of "least-squares" $(k=2.3 \times$ slope as defined in the regression equation).

Hemagglutination titrations. HA (expressed in hemagglutinating units [HAU]) was estimated in the following way. Serial twofold dilutions of the samples to be tested were made with 50 - $\mu$ liter volumes of cold phosphate- $\mathrm{NaCl}$ buffer, $p \mathrm{H} \mathrm{7.0.} \mathrm{After}$ adding an equal volume of $0.5 \%$ chicken or guinea pig erythrocytes (RBC) to each dilution, the suspensions were shaken briefly and incubated at $4 \mathrm{C}$ until the RBC controls (no virus) were clearly negative (approximately $1 \mathrm{hr}$ ). The number of HAU in an undiluted virus sample was defined as the reciprocal of that dilution showing approximately $50 \%$ agglutination. This was calculated by interpolation between the highest dilution showing complete agglutination and the next highest showing no agglutination. All titrations were run in duplicate, and duplicates that showed greater than a twofold variation in the interpolated HAU were repeated.

Estimation of neuraminidase activity. Virus suspensions were assayed for NA by using fetuin as a substrate. The amount of free sialic acid released was then assayed.

Fetuin (molecular weight $4.84 \times 10^{4}$ [31] was purchased in sterile lyophilized $500-\mathrm{mg}$ lots (GIBCO). 
These were dissolved in sterile phosphate- $\mathrm{NaCl}$ buffer, $p H 5.5$, at a final concentration of $12.5 \mathrm{mg} / \mathrm{ml}$ and stored at $-20 \mathrm{C}(4,8)$. Assuming there are 13 terminal sialic acid residues per molecule of fetuin (32), these stocks contained $3.35 \times 10^{3}$ nmoles of sialic acid $/ \mathrm{ml}$.

Reactions were carried out in $0.5-\mathrm{ml}$ volumes in identical 15-ml ground-glass-stoppered, conical centrifuge tubes (Pyrex, Corning Co., Inc.). Amounts $(0.1 \mathrm{ml})$ of sample to be assayed were diluted with $0.3 \mathrm{ml}$ of phosphate- $\mathrm{NaCl}$ buffer, $p \mathrm{H} \mathrm{5.5}$, and held in an ice bath. When $0.1 \mathrm{ml}$ of substrate $(1.25 \mathrm{mg})$ was added to each tube in series, the mixture was shaken briefly on a Vortex and either returned to the ice bath (zero-time control), or transferred to a $37 \mathrm{C}$ swirling water bath. The periodic acid reagent, used in the sialic acid assay, was included in the controls and added to the incubating mixtures to stop the reaction at $10 \mathrm{~min}$ or $2 \mathrm{hr}$ depending on whether the $\mathrm{HA}$ of the material being assayed was $\leq 1,024$ or $\leq 100 \mathrm{HAU}$, respectively. Under these conditions, substrate was hydrolyzed linearly with time.

Sialic acid was assayed by the thiobarbituric acid method of Aminoff (1) with the following modifications. (i) Chromophore was extracted (more efficiently) from warm preparations. (ii) In reaction mixtures containing small amounts of free sialic acid, chromophore was extracted into $2.5 \mathrm{ml}$ of acidbutanol $(10 \%$ [v/v] $12.3 \mathrm{M} \mathrm{HCl})$. (iii) Optical density readings could be made up to $8 \mathrm{hr}$ after chromophore development if the tubes were kept tightly sealed during this period; otherwise, absorbancies began to decrease after $2 \mathrm{hr}$.

Phospholipase-C treatment. Lyophilized 100mg lots of phospholipase-C (Nutritional Biochemicals Co.) were rehydrated at a final concentration of 2 $\mathrm{mg} / \mathrm{ml}$ in Tris- $\mathrm{CaCl}_{2}$-albumin buffer $(0.05 \mathrm{M}$ Trishydrochloride $[p \mathrm{H} 7.8], 0.001 \mathrm{M} \mathrm{CaCl}_{2}, 0.1 \%$ bovine serum albumin). Virus was dialyzed against the same buffer and treated with lipase at $37 \mathrm{C}$ for 10 min according to the method of Friedman and Pastan (14). Reaction mixtures containing both EDTA and lipase served as controls for the following reasons. (i) The concentration of lipase in the reaction mixtures $(1 \mathrm{mg} / \mathrm{ml})$ partially protected $\mathrm{HA}$ and NA against thermal inactivation. (ii) The final concentration of EDTA (2 mmoles/liter) completely inhibited the action of the divalent cation-requiring lipase. (iii) The amount of EDTA carried over into the neuraminidase reaction system (final concentration: $0.4 \mathrm{mmole} /$ liter) did not inhibit NA.

In preliminary experiments (not reported here) the commercial lots of lipase were found to be contaminated with significant amounts of a neuraminidase. This activity was inactivated within $4 \mathrm{~min}$ at $56 \mathrm{C}$ in the above reaction mixtures. Therefore, when appropriate, lipase controls were run so that this nonviral contribution to the total activity could be substracted.

Spectrophotometry. Optical densities were determined with the Gilford spectrophotometer by using matched 1-ml quartz cuvettes with a $1-\mathrm{cm}$ light path.

\section{RESULTS}

Selection of strains. When the relative thermal stability of HA was determined for each of the nine NDV strains, the Texas-GB strain (strain I) showed the greatest stability, with a rate constant for inactivation at $56 \mathrm{C}$ of only $0.05 \mathrm{~min}^{-} 1$. All other strains were considerably more thermosensitive. The New Jersey FRB strain (strain V) was most sensitive, with a rate constant of $0.31 \mathrm{~min}^{-1}$.

Influence of external factors on the rates of inactivation. IAFs used in the preliminary screening experiments contained various amounts of egg yolk and virus. To determine whether the apparent difference in the rate of inactivation between strains $\mathrm{I}$ and $\mathrm{V}$ was a function of their HA per se, or due in part to protective environmental and virus concentration effects, the thermal stability of HA was closely monitored in both partially purified virus concentrates and in clarified IAFs (Fig. 1). The solid lines in Fig. 1a show that the HA of strain I was inactivated in buffer at a constant rate of approximately $0.18 \mathrm{~min}^{-1}$ in virus suspensions that initially titrated between 160 and 20,000 HAU. Similarly, in this medium no concentration-dependent changes in rate were evident from the kinetics with which the HA of strain $\mathrm{V}$ was inactivated (dotted lines in Fig. 1a). Although this was also true for both strains in the form of IAF (Fig. 1b), the rates of inactivation in allantoic fluid were roughly 10-fold slower than those characteristic of inactivation in buffer. However, despite the protective effect of allantoic fluid, the ratio of the inactivation rates for the two strains was the same in both buffer and allantoic fluid.

Thermal stability of HA among isolates cloned from phenotypically stable (strain I) and sensitive (strain $V$ ) populations. The first-order kinetics with which the $\mathrm{HA}$ of strains I and V were inactivated indicated that neither population contained a major clone of the opposite thermal phenotype. However, it was of interest to know what degree of variation, if any, might be resolved among isolates cloned from these populations. To this end, 73 isolates were obtained. In the case of 32 of these isolates the inactivation rate constants for HA were determined accurately; results are summarized in Table 1 . In general the rates varied only 2- to 2.5 -fold among isolates cloned from the same population. A difference of a factor of 2 is probably not significant. Isolate $I_{16}$ was the single exception. Its HA was 6 - to 14 -fold more thermolabile than that 


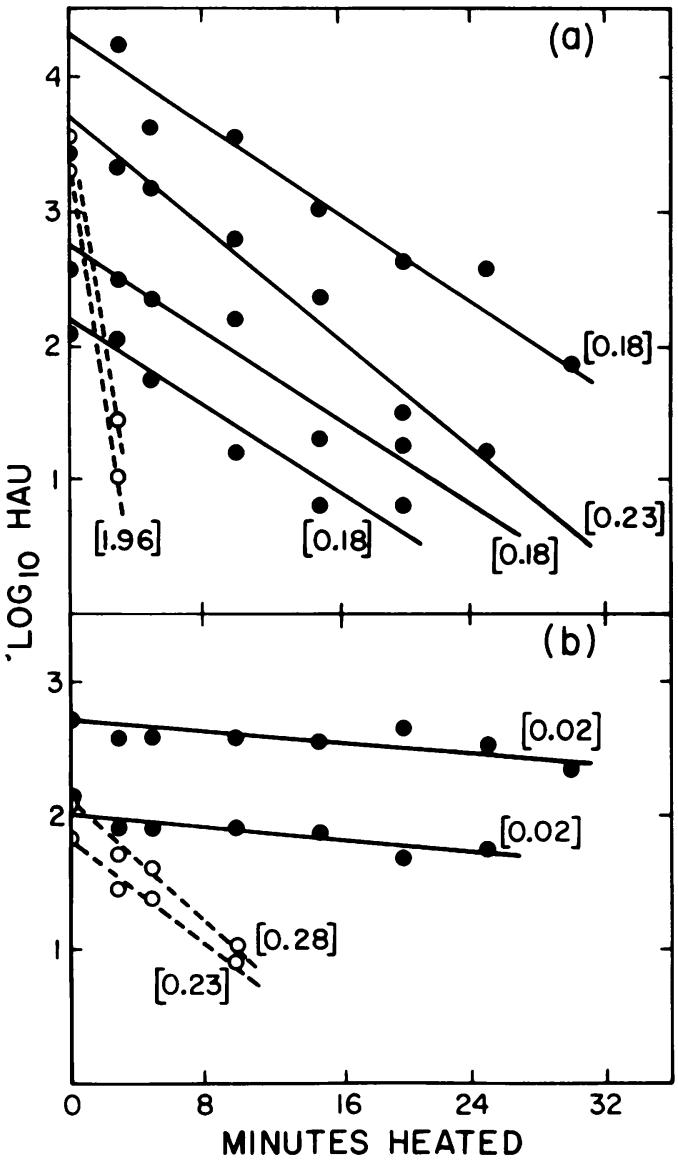

Fig. 1. Effect of virus concentration on the thermal inactivation rate of $H A$ by strains $I$ and $V$. (a) In buffer. Virus from 25-ml amounts of IAF was centrifuged onto potassium tartrate cushions. The resulting virus concentrates were dialyzed and adjusted to different concentrations in Tris-EDTA-NaCl buffer, $\mathrm{pH}$ 8.0. (b) In allantoic fluid. IAFs were diluted with normal yolk-free allantoic fluid, $\mathrm{pH} 8$ to 8.5. Samples $(0.2 \mathrm{ml})$ of virus prepared by either method were heated for the indicated times. Surviving $H A$ was measured against chicken $R B C$. Rate constants are given in brackets. Strain I (O- - ) Strain V (O- - -O).

of any other strain I isolate and in fact was inactivated at a rate comparable to those of the strain $\mathrm{V}$ isolates.

Subsequently, the relative thermal stability of HA was determined for similar preparations of the remaining isolates. When the HA titers were adjusted to approximately 1,000 HAU and $0.2-\mathrm{ml}$ volumes were heated for only 5 min, $\mathrm{HA}$ in the 20 remaining strain $\mathrm{V}$ isolates was inactivated at a rate of $>1.4 \mathrm{~min}^{-1}$, and none of the 21 remaining strain $I$ isolates was inactivated at a rate of $>0.3 \mathrm{~min}^{-1}$.
HA inactivation and virus integrity. Thus far, HA inactivation was defined in terms of the ability of virus to agglutinate chicken RBC. However, the efficiency with which a given $\mathrm{RBC}$ species is agglutinated can vary with the size of the hemagglutinating particles. For example, intact myxovirus particles and large envelope fragments agglutinate chicken RBC with a two- to eightfold greater efficiency than they do guinea pig RBC (personal observation). Conversely, low-molecular-weight hemagglutinin derived from the virus agglutinates guinea pig $\mathrm{RBC}$ much more efficiently than chicken RBC (12). Therefore, while it was presumed that HA in the intact virus envelope was being measured, the observed thermal lability of the HA in the thermosensitive isolates might have been a function of virus disruption resulting in the fragmentation of the envelope into units that were too small to agglutinate fowl $\mathrm{RBC}$, but which might have agglutinated guinea pig RBC. Alternatively, the loss of HA might have been due to the loss of hemagglutinin spikes without further disruption of the envelope. In such a case, the buoyant density of the resulting particle might be different from that of the intact virion (4). These

TABLE 1. Variation in the thermal stability of $H A$ among isolates cloned from phenotypically stable $(I)$ and sensitive (V) strains

\begin{tabular}{|c|c|c|c|c|}
\hline \multirow[b]{2}{*}{ Isolates $^{a}$} & \multicolumn{2}{|c|}{ Strain I } & \multicolumn{2}{|c|}{ Strain V } \\
\hline & $\begin{array}{c}\text { Original } \\
\log _{10} \mathrm{HAU}^{0}\end{array}$ & $\begin{array}{l}\text { Rate } \\
\text { constant } \\
\left(\mathrm{min}^{-1}\right)\end{array}$ & $\begin{array}{c}\text { Original } \\
\log _{10} \mathrm{HAU}\end{array}$ & $\begin{array}{c}\text { Rate } \\
\text { constant } \\
\left(\min ^{-1}\right)\end{array}$ \\
\hline 1 & 2.23 & 0.12 & 2.05 & 1.20 \\
\hline 2 & 2.20 & 0.14 & 4.13 & 1.31 \\
\hline 3 & 3.60 & 0.14 & 2.00 & 1.38 \\
\hline 4 & 3.00 & 0.18 & 3.10 & 1.43 \\
\hline 5 & 2.50 & 0.18 & 3.34 & 1.50 \\
\hline 6 & 3.58 & 0.18 & 2.91 & 1.52 \\
\hline 7 & 1.75 & 0.21 & 1.93 & 1.54 \\
\hline 8 & 3.72 & 0.23 & 2.16 & 1.61 \\
\hline 9 & 3.60 & 0.23 & 1.95 & 1.72 \\
\hline 10 & 3.08 & 0.23 & 2.75 & 1.84 \\
\hline 11 & 3.50 & 0.23 & 4.16 & 1.86 \\
\hline 12 & 2.50 & 0.25 & 2.85 & 1.89 \\
\hline 13 & 2.70 & 0.25 & 3.25 & 1.89 \\
\hline 14 & 3.89 & 0.30 & 2.45 & 2.30 \\
\hline 15 & 1.80 & 0.30 & 5.27 & 2.37 \\
\hline 16 & 2.43 & 1.66 & 2.40 & 2.58 \\
\hline
\end{tabular}

${ }^{a}$ Each isolate was passaged once in eggs. Partially purified virus concentrates were prepared and then thermally inactivated as described in Fig. 1. Regression equations describing the inactivation of strain $I$ and strain $V$ isolates were calculated from 4 to 5 and 7 to 10 points, respectively. The HA titer of the unheated suspension was omitted in each calculation because inactivation was not exponential during the first 30 sec of heating.

- The ordinate value calculated by extrapolation to zero minutes of heating. 
possibilities were examined in the following experiment.

Isolate $I_{16}$ was purified in potassium tartrate gradients to eliminate the HA that was not associated with intact particles. Then, a portion of the purified virus suspension was heated until the HA against chicken $\mathrm{RBC}$ was reduced to $15 \%$ of the initial titer. Figure 2 shows that, when samples of the heated and unheated suspensions were sedimented under conditions that locate the intact virus at its isopycnic density, the density distribution of the HA remaining after heating was indistinguishable from that of the unheated virus. HA against guinea pig RBC was two- to fourfold less than it was against chicken RBC, but the distribution of activity against either cell type was the same. HA per fraction was expressed as the $\log _{10}$ HAU which masked the slight skewing of the profiles toward the less dense region of the gradients. However, when the data were plotted on a linear scale (not shown), the same degree of asymmetry was evident in both profiles; 93 and $95 \%$ of the HAU recovered was in five (Fig. 2a) and four (Fig. 2b) peak fractions, respectively. Optical density and HA profiles both peaked at a mean buoyant density of $1.19 \mathrm{~g} / \mathrm{ml}$. No preferential activity against guinea pig RBC was evident in fractions of lower density. Significantly, integration under the optical density profiles showed that the peak regions contained approximately the same number of optical density units; i.e., 4.1 (Fig. 2a) and 3.8 (Fig. 2b). Thus, inactiva-

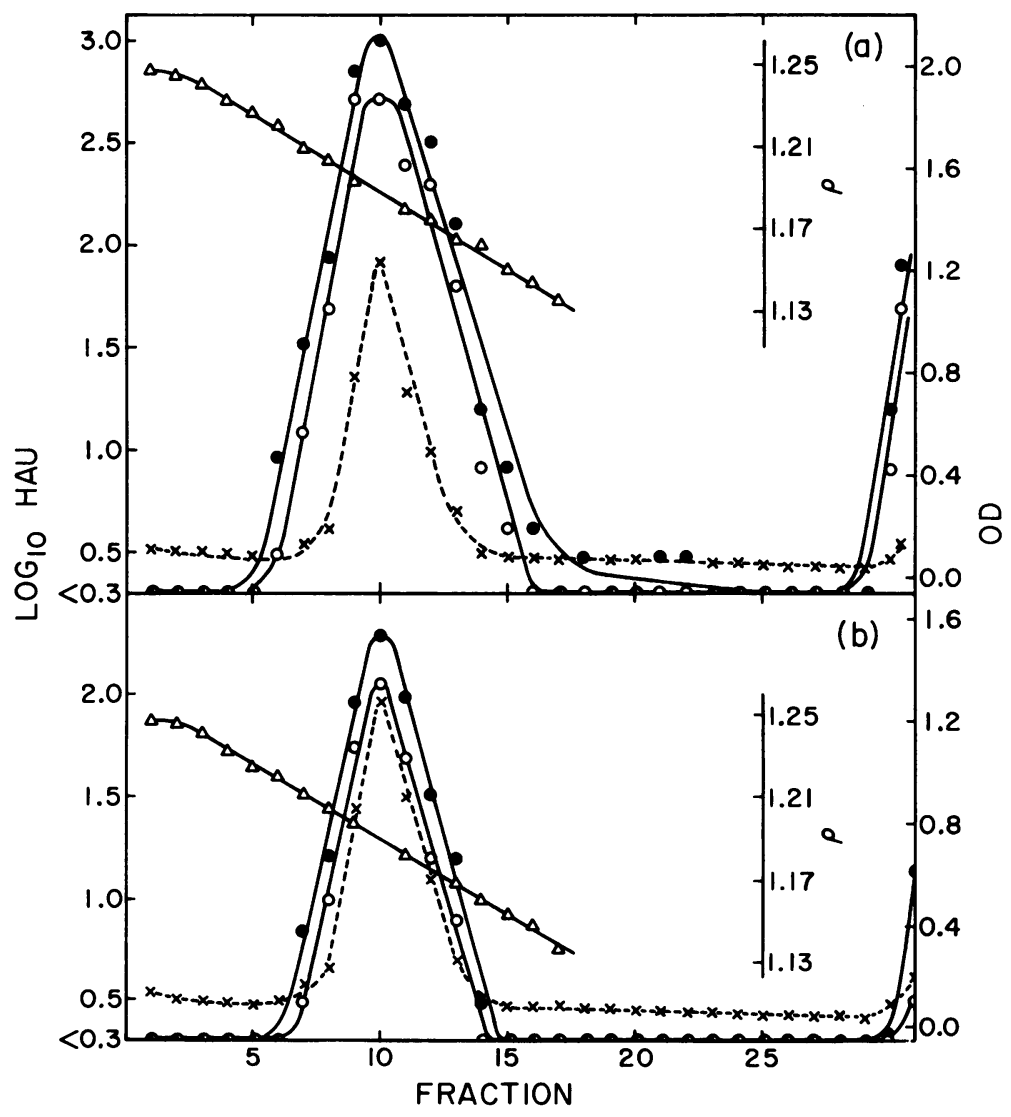

FIG. 2. Effect of heating on the buoyant density of HA. Purified egg-grown isolate $I_{18}$ was dialyzed against Tris-EDTA-NaCl buffer, $\mathrm{pH}$ 8.0. The sample, initially titrating to 1,800 HAU against chicken RBC, was treated at $56 \mathrm{C}$ to reduce the titer by a factor of 6 . Samples $(2 \mathrm{ml})$ of the heated and an unheated control suspension were layered onto separate $24-m l$ potassium tartrate gradients (10 to $40 \%, w / v$, in the above buffer). The tubes were centrifuged for $4.5 \mathrm{hr}$ at $25,000 \mathrm{rpm}$ and then fractionated from the bottom $(0.84 \mathrm{ml}$ per fraction). The optical density $(O D)$ at $260 \mathrm{~nm}(\times----\times)$, density $(\rho)$ in grams/milliliter $(\Delta--\Delta)$, and $H A$ titer $\left(\log _{10} H A U\right)$ against chicken $R B C\left(O_{-}\right)$) and guinea pig $R B C(0-O)$ were determined for each fraction. Sedimentation was from right to left. (a) Not heated (30.4 fractions); (b) heated (31 fractions). 
tion of HA was not accompanied by any detectable virus disruption.

Comparative thermal inactivation rates of HA, NA, and infectivity. The thermal inactivation of isolate $\mathrm{I}_{16} \mathrm{HA}$ apparently involved some alteration at the virus surface exclusive of either envelope fragmentation or the loss of hemagglutinin spikes. Because of the proximity and in some cases the probable association of the structural units responsible for $\mathrm{HA}$ and NA $(3,18,19,25,33,34)$, an experiment was designed to compare the rates of inactivation of these envelope activities at $56 \mathrm{C}$. Small volumes of IAF of isolate $I_{1}$ and $I_{16}$ were heated for different times up to $6 \mathrm{~min}$ and assayed for remaining $\mathrm{HA}$ and NA (Fig. 3). In the case of isolate $I_{1}$, both activities were relatively stable with rate constants for inactivation of $<0.05$ $\min ^{-1}$; however, both activities in isolate $I_{16}$ were inactivated at a rate that was at least 10 times faster than that for isolate $I_{1}$. Significantly, the HA and NA of isolate $I_{16}$ were inactivated at the same rate within experimental error (4.1 $\mathrm{min}^{-1}$ and $4.6 \mathrm{~min}^{-1}$, respectively).

In a second experiment, the relative rates of inactivation of infectivity as well as HA and NA of isolates $I_{1}, I_{16}$, and $V_{1}$ were determined during a $40-\mathrm{min}$ period at $56 \mathrm{C}$ (Fig. 4).

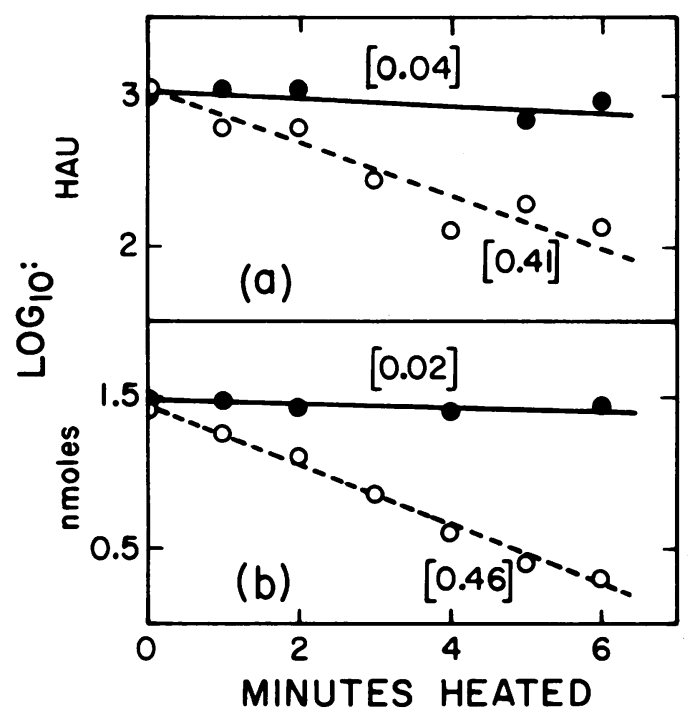

Fig. 3. Comparison of thermal inactivation rates of $H A$ and NA. Four 0.1-ml IAF samples of both isolate $I_{1}\left(O_{-}\right)$and isolate $I_{16}\left(O_{-}--O\right)$ were heated for each of the times indicated. Surviving $H A$ and NA were determined in duplicate samples, and the results were expressed as the $\log _{10}$ of (a) HA against chicken $R B C$ and (b) nanomoles of sialic acid released in $10 \mathrm{~min}$ by $0.1 \mathrm{ml}$ of IAF. Rate constants are given in brackets.

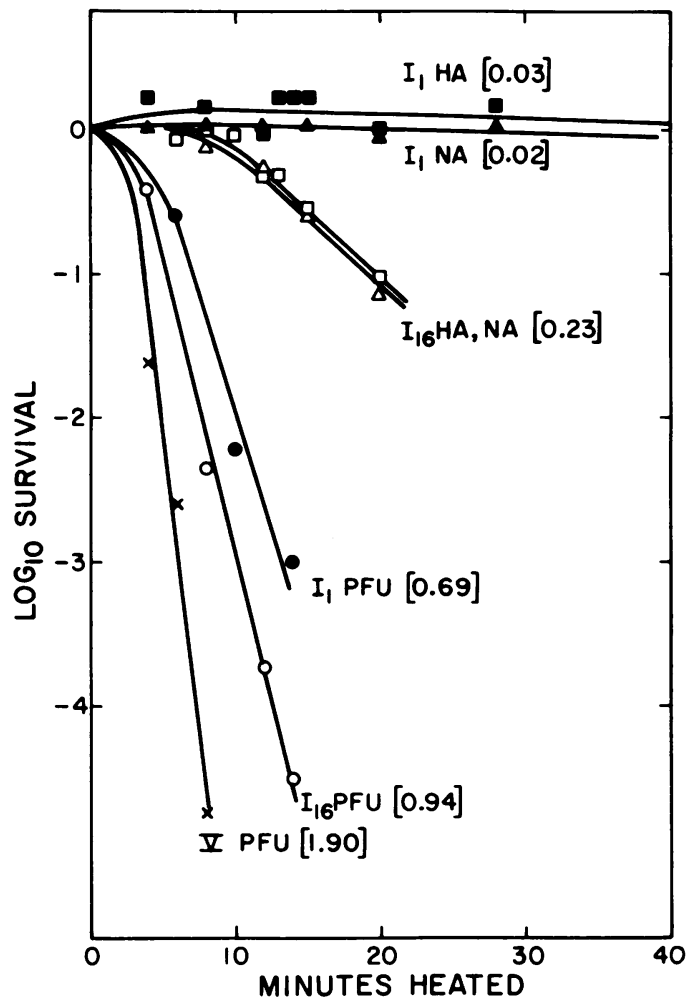

Fig. 4. Comparative thermal characters of $H A$, $N A$, and infectivity. After 1.2-ml volumes of IAF were heated for the times indicated, each was assayed for $H A$ and NA as described in Fig. 3, and for infectivity as plaque-forming units $(P F U) / m l$. Unheated $I_{1}$ and $I_{16}$ IAFs, respectively, liberated 29 and 24 nmoles of sialic acid, contained $6.9 \times 10^{8}$ and $5 \times 10^{8} \mathrm{PFU} / \mathrm{ml}$, and titrated to approximately $1024 \mathrm{HAU}$. The results are expressed as the $\log _{10}$ survival of each activity. The survival of isolate $V_{1}$ infectivity $\left(2 \times 10^{\circ} \mathrm{PFU} / \mathrm{ml}\right.$ before heating) is shown for comparison. Rate constants (numbers in brackets) were calculated from the slopes of the lines estimated during the periods of exponential decline.

The volumes of IAF heated were sufficiently large $(1.2 \mathrm{ml})$ so that all three activities could be determined in the same sample for each period of heating. Because of the large volume heated, however, it required 4 to $7 \mathrm{~min}$ to bring the sample to temperature, and thus the inactivation of the various activities became exponential only after several minutes of heating. (The slow initial inactivation at lower temperatures is to be expected because the enthalpy of inactivation for this system is large, and the rate constant thus shows a steep temperature dependence.)

The results in Fig. 4 again illustrate that the HA and NA inactivate at the same rates, and 
that isolate $\mathrm{I}_{16}$ activities inactivate more rapidly than those of isolate $I_{1}$. The absolute value of the rate constant for $I_{18}$ differs by a factor of 2 from that found in Fig. 3, probably because of slight temperature differences or differences in the degree of protection provided by the allantoic fluid. The $\mathrm{HA}$ and NA of isolate $\mathrm{V}_{1}$ (not shown) inactivated at a rate indistinguishable from that found for $I_{16}$.

The infectivities of all three virus preparations inactivated much more rapidly. The rate constants for inactivation of infectivity during the period of exponential decline were 0.69 $\min ^{-1}$ for isolate $I_{1}, 0.94 \mathrm{~min}^{-1}$ for isolate $I_{16}$, and $1.9 \mathrm{~min}^{-1}$ for isolate $V_{1}$. The inactivation rates of infectivity for isolates $I_{1}$ and $I_{16}$ differ by a factor of only 1.4, although the inactivation rate of $\mathrm{HA}$ (and NA) in these two isolates differs by approximately a factor of 10 . Thus, although the thermal inactivation of HA is correlated with loss of NA, the inactivation of infectivity is not correlated with the loss of either of these activities.

Effect of phospholipase-C on the thermal inactivation of HA and NA. NDV infectivity was reported to be more thermolabile when the virus was grown in monolayers of chicken embryo fibroblasts rather than in chick chorioallantoic membranes (7). This difference in stability may be due to a difference in the lipid composition of the virus. Phospholipase-C treatment of NDV was reported to inactivate virus infectivity, if the virus were grown in chick fibroblast but not if grown in eggs (30), indicating that the virus has a different lipid composition when grown in the two cell systems.

The experiments summarized in Fig. 5 were done to test for the possible role these lipids (primarily lecithin) might have in conferring a particular thermal stability onto $\mathrm{HA}$ and NA. The results show that pretreating isolates $I_{1}$ and $I_{16}$ with phospholipase-C did not alter their thermal stability when the virus was grown in eggs (Fig. 5 a-d); however, it did reduce the thermal stability of HA in both isolates grown in monolayers (Fig. 5 e, f). During the first 6 to $8 \mathrm{~min}$ of heating, their HA dropped three- to fourfold. Thereafter, the residual HA of isolate $I_{1}$ remained stable, while that of isolate $I_{16}$ was inactivated at a rate similar to that of the untreated $\mathrm{I}_{16}$ control. The thermal character of NA in both isolates grown in monolayers was not affected by this lipase (Fig. $5 \mathrm{~g}, \mathrm{~h}$ ).

HA in these experiments was measured against chicken RBC. During the course of titrating monolayer-grown virus that had been

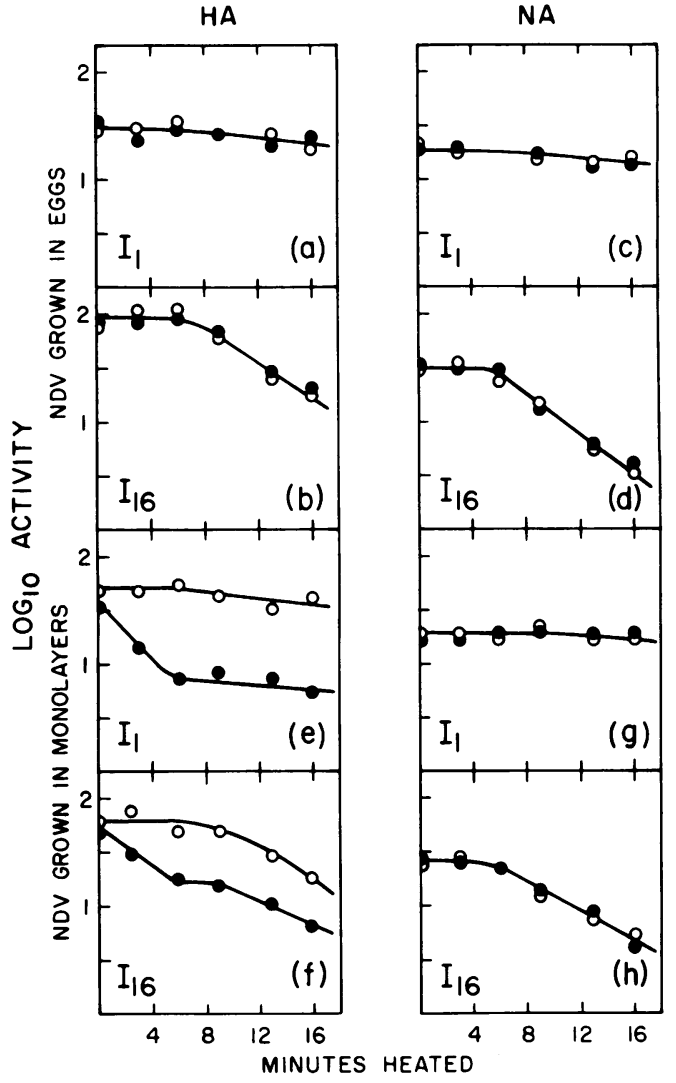

Fig. 5. Effect of phospholipase-C on the rates of inactivation of HA and NA. Suspensions of purified egg-grown and monolayer-grown isolates $I_{1}$ and $I_{16}$ in Tris-CaCl $\mathrm{Cl}_{2}$-albumin buffer were incubated at $37 \mathrm{C}$ for 10 min with an equal volume of the same buffer that contained phospholipase in the presence $(\mathrm{O}-\mathrm{O})$ and absence (-) of sufficient EDTA to completely inhibit lipase activity. Samples $(1 \mathrm{ml})$ of these were then heated for the times indicated. Each was then assayed for surviving HA (HAU against chicken $R B C$ ) and NA (nanomoles of sialic acid released in $2 \mathrm{hr}$ per 0.1-ml sample).

treated with lipase in the absence of EDTA, as the RBC were settling out, some evidence of agglutination was noticed at higher dilutions than in those from which the end points were ultimately interpolated. This was only true in the titration series of samples heated at $56 \mathrm{C}$. This suggested that the observed initial drop in HA was caused by the disruption of the virus envelope into fragments that agglutinated chicken RBC with a three- to fourfold lower efficiency. This interpretation was confirmed when HA was measured against guinea pig RBC (Fig. 6). Under these conditions HA in similar suspensions of isolate $I_{1}$ actually increased during the first 6 to $8 \mathrm{~min}$ of heating. 


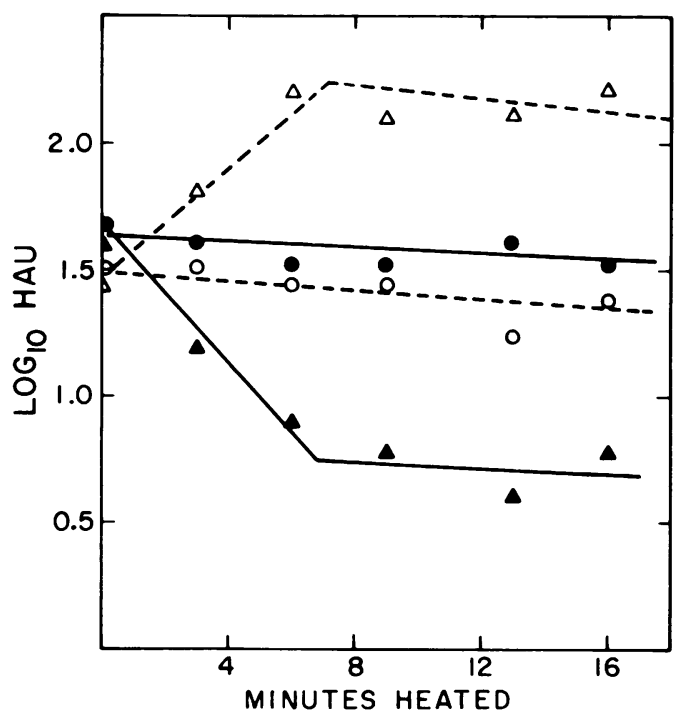

Fig. 6. Effect of phospholipase-C on the rates of inactivation of $H A$ measured against fowl and guinea pig RBC. A suspension of purified monolayer-grown isolate $I_{1}$ was treated with lipase in the presence (circles) and absence (triangles) of EDTA as described in Fig. 5. Samples $(1 \mathrm{ml})$ of these mixtures were heated for the times indicated. The survival of HA was measured against chicken (closed symbols) and guinea pig (open symbols) $R B C$.

\section{DISCUSSION}

We are interested in the nature of the components of biological membranes and the mechanisms by which these components interact to form a functional structure. Analyses of these interactions would be significantly more illustrative if a membrane system were available in which any one of its associated activities could be altered independently of any other activity. Then, a given change in function might be more specifically correlated with the responsible physicochemical change(s) in the membrane.

NDV would seem to provide just such a system because its envelope, or membrane, possesses several surface activities which are apparently properties of independent envelope moieties $(17,20,24)$, and thus the thermal stability of any one activity might be expected to vary independently from those of the other activities. Therefore, the approach used in the study reported here was to characterize accurately the thermal stability of two surface activities, expecting that virus isolates could be selected that differed markedly in the thermal stability of a single envelope activity. However, when the rate of thermal inactivation of NA was determined for isolates chosen because of their differing HA stabilities, NA was found to inactivate at a rate identical to that for the inactivation of HA. We have also isolated a number of mutants of NDV, selected to be altered only in the thermal stability of their NA. In every case, the thermal stability of HA of these mutants was altered in parallel (Pierce, Goldsby, and Haywood, manuscript in preparation).

We can envision several mechanisms which might lead to the coupling of these two activities. It is conceivable that the same glycoprotein is responsible for both activities. This, however, is highly unlikely in view of the fact that myxoviral HA and NA reside in morphologically distinct structures that can be readily separated $(8,17,21,34)$.

It is possible that alteration of one of the viral proteins, either external or internal, could lead to an altered lipid composition or organization in the virus. This could in turn affect the thermal stability of both activities. However, it is unclear at the present time how dependent the lipid composition of a virus is upon its proteins $(3,6,18,22,23,28,29,34)$. Alternatively, although we know of no precedent for such a mechanism, an alteration in one of the proteins which affected a charged group could affect the stability of both activities.

The possibility also exists that denaturation of the protein responsible for one activity could lead to a configurational rearrangement of the viral surface such that the protein with the other activity either becomes more labile or has its expression blocked in some way. In the latter case, for example, a concomitant loss of HA and NA might be expected if HA inactivation were due to a "folding over" of the hemagglutinin spikes. In this configuration the spikes might interfere with the binding of substrate at the sites of NA. In this regard it may be significant that residual NA was estimated only against fetuin. A smaller substrate molecule might have been more accessible to potentially active, but perhaps partially "masked," neuraminidase sites on the surface of particles with thermally inactivated HA. Different-sized substrates probably do interact differently with the virus surface. For example, not only the apparent affinity of neuraminidase for substrate (2, 9), but also the kinetics of substrate hydrolysis can vary with the size of the substrate molecule. That is, sialolactose (molecular weight 633) is hydrolyzed with classical first-order MichaelisMenten kinetics, whereas fetuin (molecular weight 48,400 ) is hydrolyzed early in the reaction with second-order kinetics, suggesting that two molecules of fetuin are required for 
the hydrolysis of one (Pierce and Magee, manuscript in preparation). We do not yet know how this mode of interaction may influence, if at all, the observed coupling between the thermal inactivation of $\mathrm{HA}$ and NA.

\section{ACKNOWLEDGMENTS}

We thank James H. Strauss, Jr., and Ellen G. Strauss for their constructive editorial advice during the preparation of this manuscript.

This investigation was supported by Public Health Service grant AI 07788 from the National Institute of Allergy and Infectious Diseases.

\section{ADDENDUM IN PROOF}

During the preparation of this manuscript, $A$ Scheid et al. (Virology 50:640, 1972) reported that the hemagglutinating and neuraminidase activities of the parainfluenza virus, SV5, reside in a single viral protein.

\section{LITERATURE CITED}

1. Aminoff, D. 1961. Methods for the quantitative estimation of $\mathrm{N}$-acetylneuraminic acid and their application to hydrolysates of sialomucoids. Biochem. J. 81:384392.

2. Brostrom, M. A., G. Bruening, and R. A. Bankowski. 1971. Comparison of neuraminidase of paramyxoviruses with immunologically dissimilar hemagglutinins. Virology 46:856-865.

3. Choppin, P. W., H-D. Klenk, R. W. Compans, and L. A. Caliguiri. 1971. The parainfluenza virus SV5 and its relationship to the cell membrane, p. 127-156. In M. Pollard (ed.), From molecules to man, prospectives in virology, vol. 7. Academic Press Inc., New York.

4. Compans, R. W. 1971. Location of the glycoprotein in the membrane of Sindbis virus. Nature N. Biol. 229: 114-116.

5. Darrell, R. W., and C. Howe. 1964. The neuraminidase of parainfluenza virus (type 2). Proc. Soc. Exp. Biol. Med. 116:1091-1094.

6. David, A. E. 1971. Lipid composition of Sindbis virus. Virology 46:711-720.

7. Drake, J. W., and P. A. Lay. 1962. Host-controlled variation in NDV. Virology 17:56-64.

8. Drzeniek, R., H. Frank, and R. Rott. 1969. Electron microscopy of purified influenza virus neuraminidase. Virology 36:703-707.

9. Drzeniek, R., J. T. Seto, and R. Rott. 1966. Characterization of neuraminidase from myxoviruses. Biochim. Biophys. Acta 128:547-558.

10. Duesberg, P. H., and W. S. Robinson. 1965. Isolation of the nucleic acid of Newcastle disease virus (NDV). Proc. Nat. Acad. Sci. U.S.A. 54:794-800.

11. Dutcher, R. M., R. B. Read, and W. Litsky. 1960. The immunological antigenicity of rapid heat inactivated viruses. I. Newcastle disease virus. Avian Dis. 4:205217.

12. Eckert, A. 1967. Envelope protein of influenza virus. J. Virol. 1:920-927.

13. Francis, T., Jr. 1947. Dissociation of hemagglutinating and antibody measuring capacities of influenza virus. J. Exp. Med. 85:1-7.

14. Friedman, R. M., and I. Pastan. 1969. Nature and function of structural phospholipids of an arbovirus. J. Mol. Biol. 40:107-115.
15. Howe, C., L. T. Lee, and H. M. Rose. 1961. Collocalia muccoid: a substrate for myxovirus neuraminidase. Arch. Biochem. Biophys. 95:512-520.

16. Hsiung, G. D. 1964. In G. D. Hsiung and J. R. Henderson (ed.), Diagnostic virology. Yale University Press, New Haven, Conn.

17. Iinuma, M., T. Yoshida, Y. Nagai, K. Maeno, T. Matsumoto and M. Hoshino. 1971. Subunits of NDV. Hemagglutinin and neuraminidase subunits of Newcastle disease virus. Virology 46:663-677.

18. Klenk, H-D., and P. W. Choppin. 1970. Plasma membrane lipids and parainfluenza virus assembly. Virology 40:935-947.

19. Klenk, H-D., R. Rott, and H. Becht. 1972. On the structure of the influenza virus envelope. Virology 47:579591.

20. Kohn, A., and C. Klibansky. 1967. Studies on the inactivation of the cell-fusing property of NDV by phospholipase A. Virology 31:385-388.

21. Laver, W. G., and R. C. Valentine. 1969. Morphology of the isolated HA and neuraminidase subunits of influenza virus. Virology 38:105-119.

22. Lazarowitz, S. G., R. W. Compans, and P. W. Choppin. 1971. Influenza virus structural and nonstructural proteins in infected cells and their plasma membranes. Virology 46:830-843.

23. McSharry, J. J., and R. R. Wagner. 1971. Lipid composition of purified vesicular stomatitis viruses. J. Virol. 7:59-70.

24. Neurath, A. R. 1964. Association of Sendai virus with esterase and leucine aminopeptidase activity; its probable relationship to "hemolysin". Z. Naturforsch. Ser. B 19:810-814.

25. Noll, H., T. Aoyagi, and J. Orlando. 1962. The structural relationship of sialidase to the influenza virus surface. Virology 18:154-158.

26. Picken, J. C., Jr. 1964. Thermostability of Newcastle disease virus, p. 167-188. In R. P. Hanson (ed.), Newcastle disease virus: an evolving pathogen. University of Wisconsin Press, Madison.

27. Pons, M. W. 1967. Studies on influenza virus ribonucleic acid. Virology 31:523-531.

28. Quigley, J. P., D. B. Rifkin, and E. Reich. 1971. Phospholipid composition of Rous sarcoma virus, host cell membranes, and other enveloped RNA viruses. Virology 46:106-116.

29. Renkonen, O., L. Kääräinen, K. Simons, and C. G. Gahmberg. 1971. The lipid class composition of Semliki Forest virus and of plasma membranes of the host cells. Virology 46:318-326.

30. Simpson, R. W., and R. E. Hauser. 1966. Influence of lipids on the viral phenotype. I. Interaction of myxoviruses and their lipid constituents with phospholipases. Virology 30:684-697.

31. Spiro, R. G. 1960. Studies on fetuin, a glycoprotein of fetal serum. I. Isolation, chemical composition, and physiochemical properties. J. Biol. Chem. 235:28602869.

32. Spiro, R. G. 1962. Studies on fetuin, a glycoprotein of fetal serum. II. Nature of carbohydrate units. J. Biol. Chem. 237:382-388.

33. Tiffany, J. M., and H. A. Blough. 1970. Models of structure of the envelope of influenza virus. Proc. Nat. Acad. Sci. U.S.A. 65:1105-1112.

34. Webster, R. G., and R. W. Darlington. 1969. Disruption of myxoviruses with Tween 20 and isolation of biologically active hemagglutinin and neuraminidase subunits. J. Virol. 4:182-187. 